\title{
DEVELOPING PSYCHOLOGICAL EMPOWERMENT AND PATIENT SAFETY CULTURE: A PRE-EXPERIMENTAL STUDY
}

\author{
Aysegul Yilmaz ${ }^{1}$, Sergul Duygulu² \\ ${ }^{1}$ Konya Beyhekim Training and Research Hospital, Turkey \\ ${ }^{2}$ Hacettepe University Faculty of Nursing, Ankara, Turkey
}

Address for Correspondence: PhD RN. Aysegul Yilmaz, E-mail: yaysegul78@gmail.com
Received: 04.04 .2021 ; Accepted: 20.04.2021; Available Online Date: 27.05 .2021
@Copyright 2021 by Dokuz Eylül University, Institute of Health Sciences - Available online at https://dergipark.org.tr/en/pub/jbachs

Cite this article as: Yilmaz A, Duygulu S. Developing Psychological Empowerment and Patient Safety Culture: A Pre-experimental StudyJ Basic Clin Health Sci 2021; 2: 94-103.

\begin{abstract}
Aims: This study aimed to examine the development of the perceptions of the psychological empowerment and patient safety culture among Turkish nurses by implementing a training-based empowerment program for unit charge nurses.

Methods: A pre-experimental, one-group pretest-posttest test design was used. The sample consisted of $(n=38)$ unit charge nurses and $(n=174)$ staff nurses; the program included theoretical components, group work, and individual study assignments. Data was collected using the Demographic Data Sheet, Psychological Empowerment Scale and Hospital Survey on Patient Safety Culture before, immediately after, and four months after the program. Data were analysed by percentages, repeated measures analysis of variance, and the Friedman analysis was used for the abnormally distributed data. The Cochran's $Q$ test was used to analyze the number of events reported.

Results: There was a statistically significant increase found in the results of the Psychological Empowerment Scale's scores on the competence and meaning subscales, the mean positive response to teamwork within the unit's composite of Hospital Survey on Patient Safety Culture $(p<0.05)$, and event reporting $(p<0.001)$.

Conclusion: The results of this study suggest that creating a positive patient safety culture requires a review of the structures and processes of an organization. Creating, maintaining a desirable patient safety culture in health institutions is a long and hard process. The duration of future empowerment programs may be determined to allow for the long-term monitoring of their effects.
\end{abstract}

Key-words: empowerment program, patient safety culture, pre-experimental study, psychological empowerment, unit charge nurse.

\section{INTRODUCTION}

The institutions that provide health care services are high-risk places, and their practitioners may unintentionally harm people while providing services. The World Health Organization (WHO) reported that four out of ten patients who receive health care services in developing countries are harmed, and 134 million undesirable events occur in a year, causing the deaths of 2.6 million people (1). A patient safety culture (PSC) should be developed to provide patient 
safety to prevent these errors, and eliminate or minimize the harm caused by these errors (2).

Patient safety culture defined as "the values shared among organization members about what is important, their beliefs about how things operate in the organization, and the interaction of these with the work unit and organizational structures and systems, which together produce behavioral norms in the organization that promote safety" (3). Improving structures and processes requires changes in attitudes, beliefs, and behaviors, which are part of the organizational culture (2). For a positive safety culture, managers need to support their employees continuously, create positive working environments, establish communication-based on mutual trust, and create a shared perception of the importance of safety (4). Therefore, the role of the hospital managers is crucial.

The unit charge nurses (UCNs) responsible for managing services within the hospital units each play a significant role in creating a positive work environment, ensuring nurses' job satisfaction, maintaining safe and high-quality standards, and developing a PSC (5). It is necessary to develop UCNs' knowledge, attitudes, beliefs, practices, and perceptions about patient safety. In the literature, it is emphasized that UCNs influence the nurses they work with through the transfer of knowledge, skills, and behaviors (6) and the UCNs who are empowered on a particular subject also empower the nurses with whom they work (7). Staff nurses, who provide the closest level of healthcare services to patients 24 hours a day, seven days a week, account for the largest workforce in health care institutions and are thus, an essential workforce in changing or reestablishing PSC. For this reason, in order to develop the PSC perceptions of the staff nurses who work with UCNs, the UCNs must first be empowered about patient safety.

Upon examination of the studies related to empowerment in nursing, it is seen that two types of empowerment are mentioned, namely structural and psychological (8). Psychological empowerment is defined as motivational self-efficacy (9) and as intrinsic task motivation that occurs in four cognitions reflecting an individual's orientation to their work role: meaning, competence, self-determination, and impact (10). The four dimensions reflect an active rather than a passive orientation to the person's work role and empowered individuals to see their work situation not as 'given' but as something shaped by their actions (11).

Psychological empowered employees find their job meaningful, feel competent in their job, feel they have the right to make decisions within the organization, and think that they are effective in their job. It is of importance to enhance the UCNs' psychological empowerment. One of the most used approaches for supporting psychological empowerment is educational intervention. As Voegtlin et al. (6) emphasized, there is a positive relationship between educational interventions and psychological empowerment, and those who are empowered with education also positively affect other people in their units. Chang et al. (12) demonstrated the impact of head nurses' psychological empowerment and competence development (as a sub-dimension) through education. Educational interventions, specifically in-service education programs (13) and training sessions including group studies with nurses, supervisors, and UCNs' also contribute to developing PSC perceptions and decreasing sentinel events (1418).

In health care institutions where vital, complex, and critical care services are provided, UCNs should be psychologically empowered to encourage nurses to be willing to work, increase their ownership of the job, and take an active role in PSC practices. In this study, a training-based empowerment program was developed to empower the UCNs psychologically and improve PSC perceptions of UCNs and staff nurses. With the implementation of this program, it was predicted that the UCNs would be psychologically empowered. It was also predicted that controls over patient safety practices in the institution would increase (8). Thus, UCNs would improve their cultural perceptions and leadership skills related to patient safety, and staff nurses working with empowered UCNs would increase PSC perceptions. The study aimed to examine the development of PSC and psychological empowerment perceptions among Turkish nurses by implementing a training-based empowerment program for the UCNs.

\section{METHODS \\ Design}

In this study, a pre-experimental, one-group, pretestposttest design was used. This type of test design can be used to determine the effects of an 
Figure 1. Conceptual framework of the research

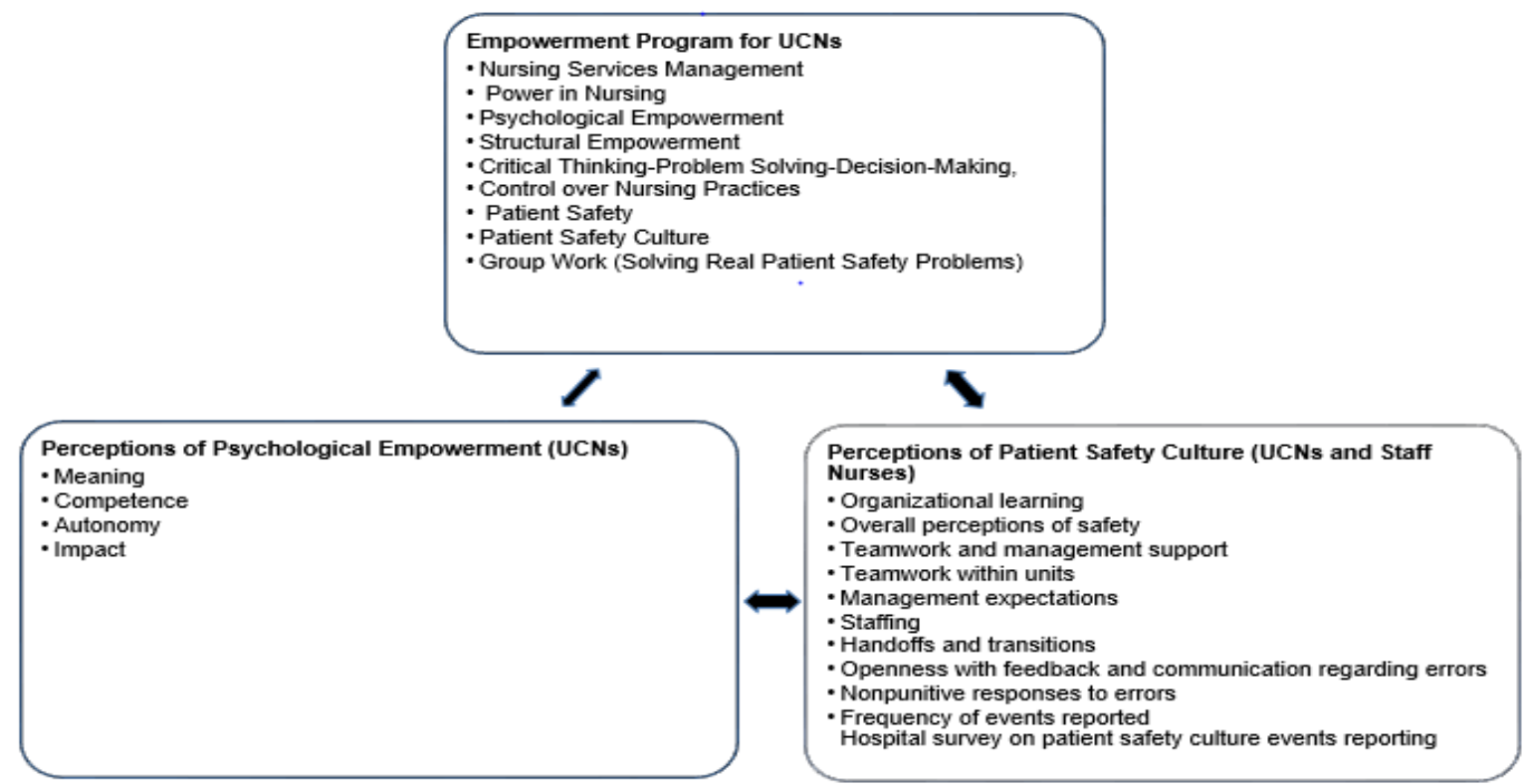

intervention/treatment on a given sample. The design has two features, including the use of a single group of participants and a linear ordering that requires assessing a dependent variable both before and after an intervention/treatment is implemented (i.e., a pretest-posttest design) (19).

This study was conducted from April 2018 through to November 2018 in the medical, surgical, intensive care unit, and emergency units of a city education and research hospital in Turkey. The hospital opened in 2017 with 1,300 beds; it was the first of its kind. Following a public-private partnership model, city hospitals provide services in a large area by bringing together several hospitals such as maternity hospitals, psychiatric hospitals, and cardiovascular hospitals, etc.).

\section{Participants}

This study included UCNs who met specific inclusion criteria: (1) each was working as a UCN during the time of the study; (2) each had at least six months experience in the position; and (3) each agreed to participate. Considering that the empowerment program could lead to a change in the moderate effect size (the moderate effect size for $F$ is $f: 0.25$ [n2: 0.06]) on the psychological empowerment scale scores of UCNs, it was determined that at least 36 people should be included for the calculation of the sample number for variance analysis in three measurements with $\mathrm{G}^{*} \mathrm{P}$ ower, with a $5 \%$ alpha error margin and $90 \%$ power. Considering the possibility of loss in the data collection, all 41 UCNs who met the criteria were included; 38 completed the study.

There were 914 nurses were working in the hospital. Five staff nurses from each unit were taken in the sample, as there were (at most) five nurses working with each UCN for at least six months in some units. It was recommended that three to eight nurses from each unit be included, based on the number available (20). A total of 191 who met the inclusion criteria agreed to participate. However, 17 were excluded for various reasons, so 174 nurses completed the study. The rate of participation was $88 \%$ for the UCNs and $91 \%$ for the staff nurses.

\section{Interventions}

The education-based empowerment program was developed and implemented by the researchers in reflection of the literature. It involved 14 hours of theoretical training (seven sessions each lasting two hours), 12 hours of group work (nine sessions with each lasting between 1 and 1.5 hours), and eight hours of individual work (six sessions with each lasting between 1 and 1.5 hours). The program was 
tested for content validity based on four academics and a head nurses' opinions, and it was finalized in line with their opinions.

\section{Theoretical Training}

In the theoretical training sessions, the aim was to increase the necessary knowledge and awareness of the UCNs relating to empowerment and PSC. It included the following subjects: Nursing Services Management, Power in Nursing, Psychological Empowerment, Structural Empowerment, Critical Thinking-Problem Solving-Decision-Making, Control over Nursing Practices, and Patient Safety and PSC. The instructors, who had expertise in the subjects, trained the UCNs in theoretical sessions (four experts and the researchers). The Empowerment Training Program Study Book was prepared by the researchers and distributed two weeks before the training for the UCNs to be prepared for each theoretical session, to carry out the relevant learning activities during and after the sessions, and to reinforce learning afterward. It included information from the literature and case studies, activities, and critical thinking questions regarding the subjects, parallel with the training subjects. As part of the session, the UCNs were asked to complete the case analyses for each session as individual activities within a specified timeframe.

\section{Group Work}

The researchers carried out the group work interactively. After the theoretical training, the UCNs identified the real patient safety problems they had experienced in their service with the staff nurses they worked with, and each UCN reported them to the researcher by e-mail. These were determined primarily based on the nurses' individual experiences and other nurses with whom they worked. The researcher formed the nine groups by classifying common/similar problems. The problems grouped as [1- Under and overtreatment or errors in administering treatment (wrong dose or wrong site administration), 2- Patient identification errors, 3Wrong-site surgery, 4- Falls, 5-Surgical site infections, 6- Communication errors, 7-Transfusion errors, 8-Adverse drug events 9-Catheter-associated urinary tract infections]. Each of the nine group work sessions lasted between 1 and 1.5 hours. Huber's problem-solving process was used, along with brainstorming, thinking aloud, employing the fishbone method, mapping concepts, conducting group discussions, and so forth (21). The UCNs having the same problems were in the same group, but all the UCNs participated in group studies simultaneously. Decisions were made to solve the problems addressed in the group studies, and each UCN cooperated with the staff nurses, other managers, and relevant units to implement these decisions. The defined solutions during the peer-supported group work sessions were implemented with the participation of the nurses. During the post-group work, two meetings were held with UCNs regarding implementing the decisions for solving the problems. They conducted presentations about what could and could not be done regarding these activities (e.g., negotiating with the units about making the bed protectors higher in the intensive care unit to prevent patient falls, meeting with the pharmacy officer regarding the delivery of expired drugs from the pharmacy, and other ideas). Within the scope of the group work, it was expected that the UCNs would share the problems related to patient safety with their staff nurses, other UCNs, and other team members of the hospital, which would contribute to the establishment of a positive PSC due to expressing and solving these problems and increasing error reporting.

\section{Individual Work Sessions}

The theoretical and group work sessions were supported by individual work. The UCNs included staff nurses with whom they worked with in individual work sessions. The UCNs, together with their staff nurses, examined the case examples related to patient safety in the Study Book. Together they answered the related questions. At the same time, they identified the problems related to patient safety experienced in their wards.

\section{Data collection procedures}

The data was collected using a demographic data sheet, the Psychological Empowerment Scale, and the Hospital Survey on Patient Safety Culture (HSOPSC). Before the study, a meeting was held with the UCNs to inform them about the program's content, its implementation, and the data collection tools to be used in the research. The demographic data sheet, Psychological Empowerment Scale, and HSOPSC were administered. Simultaneously, the demographic datasheet and the HSOPSC were given 
Table 1. Mean Scores of UCNs' Psychological Empowerment (n: 38)

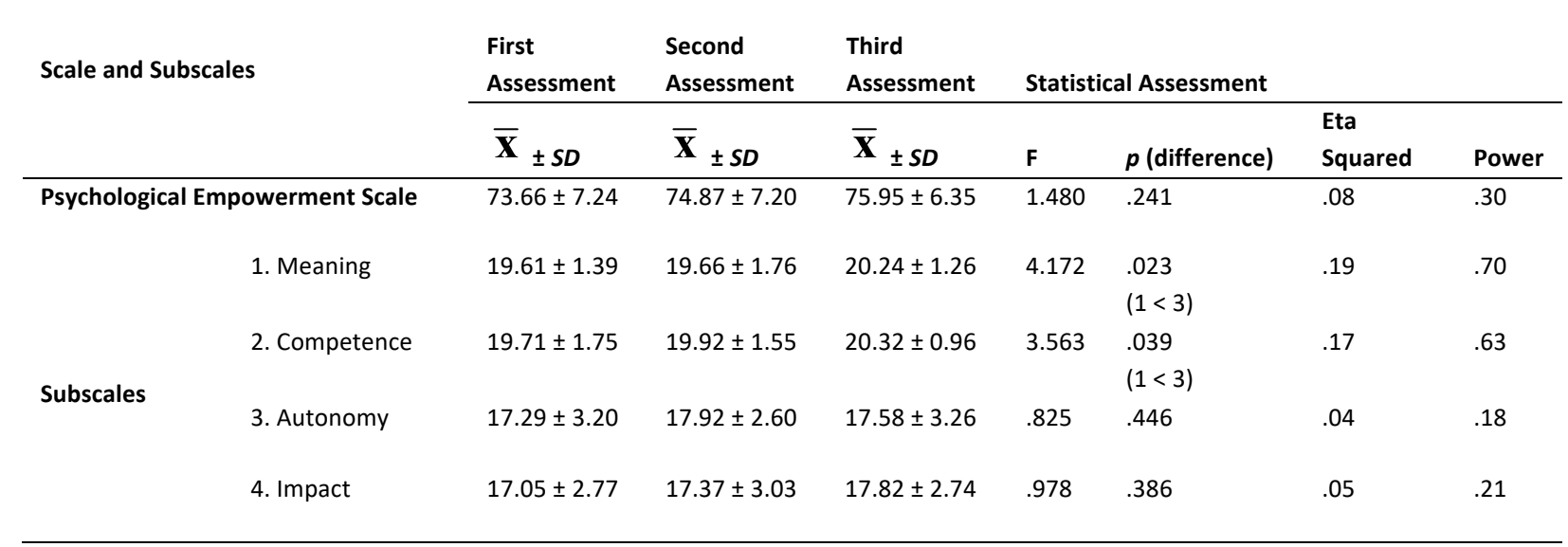

Note. F: Repeated measures analysis of variance; SD: 2 (advanced analysis Bonferroni test), standard deviation; UCN: Unit charge nurse.

to at least three staff nurses. The researcher collected the data forms in a sealed envelope. In this meeting, the program schedule was established with the UCNs.

WhatsApp and e-mail were used for constant communication with the UCNs. One week after the first administration of the data collection forms, the empowerment program's theoretical part was started. Compensatory training was given to the UCNs who could not attend the theoretical training.

After these theoretical education, group work, individual studies and meetings, the second round of the data collection was completed following the same procedure. The third round of the data collection was carried out four months after the second application.

\section{Demographic Data Sheet}

The researcher developed this form to collect the UCNs' and staff nurses' demographic information. The demographic data sheet for UCNs contained questions about age, of working year, working experience, hour working in a week and the education status regarding patient safety. The demographic data sheet for staff nurses contained questions about age, working period, the amount of time they had been working with UCNs, hour working in a week and the education status regarding patient safety.

\section{Psychological Empowerment Scale}

This scale was developed by Spreitzer, (11) and it defines psychological empowerment as having four aspects: meaning, competence, autonomy, and impact. A Turkish validity and reliability study of the scale was conducted by Uner and Turan (22). It involves a seven-point Likert scale, with one point showing that the participant never agrees. As the degree of agreement increases, the given score increases; seven points indicate that the participant entirely agrees with the expression. The scale has 12 questions, with three questions in each subscale. The psychological empowerment score is calculated as the sum of the scores. The minimum total score is 12 , indicating a low psychological empowerment perception; the maximum is 84 , indicating high psychological empowerment perception (11). Based on the Turkish reliability and validity study of the scale, the Cronbach's alpha coefficient was 0.83 (22). In this study, the Cronbach's alpha reliability coefficients of the scale were 0.88 .

\section{Hospital Survey on Patient Safety Culture (HSOPSC)}

The HSOPSC was developed by the Agency for Healthcare Research and Quality (AHRQ)(23). It emphasizes patient safety, errors, and events reporting, and consists of 42 items grouped into 12 composites. Additionally, the survey asks participants to provide an overall grade on patient safety for their work area/unit and indicate the number of events they reported in the past 12 months. Bodur and Filiz (24) adapted the survey for Turkey with 42 items under ten composites; the adaptation was related to cultural and linguistic differences. The survey has a five-point Likert scale (1 = strongly disagree/never; 2 = disagree/rarely; $\quad 3=$ neither/sometimes; $4=$ agree/most of the time, and $5=$ strongly 
Table 2. UCNs' (n: 38) and Staff Nurses' (n: 174) Mean Positive Response Percentages for PSC on the Composite Leve

\begin{tabular}{|c|c|c|c|c|c|c|c|c|c|c|c|c|c|c|}
\hline \multirow{3}{*}{$\begin{array}{l}\text { Hospital Survey } \\
\text { on Patient Safety } \\
\text { Culture }\end{array}$} & \multirow{2}{*}{\multicolumn{2}{|c|}{$\begin{array}{l}\text { First } \\
\text { Assessment (a) } \\
\overline{\mathbf{X}}_{ \pm S D}\end{array}$}} & \multirow{2}{*}{\multicolumn{2}{|c|}{$\begin{array}{l}\begin{array}{l}\text { Second } \\
\text { Assessment (b) }\end{array} \\
\overline{\mathbf{X}}_{ \pm S D}\end{array}$}} & \multirow{2}{*}{\multicolumn{2}{|c|}{$\begin{array}{l}\text { Third } \\
\text { Assessment (c) } \\
\overline{\mathbf{X}}_{ \pm S D}\end{array}$}} & \multicolumn{8}{|c|}{ Statistical Assessment } \\
\hline & & & & & & & \multicolumn{2}{|l|}{$\mathbf{F}$} & \multicolumn{2}{|l|}{$p$} & \multicolumn{2}{|c|}{ Eta Squared } & \multicolumn{2}{|c|}{ Power } \\
\hline & UCN & SN & UCN & SN & UCN & SN & UCN & SN & UCN & SN & UCN & SN & UCN & SN \\
\hline PSC (Total) & $\begin{array}{l}69.42 \pm \\
14.67\end{array}$ & $\begin{array}{l}52.31 \pm \\
21.87\end{array}$ & $\begin{array}{l}64.97 \pm \\
18.28\end{array}$ & $53.72 \pm 20.60$ & $\begin{array}{l}70.30 \pm \\
15.57\end{array}$ & $\begin{array}{l}52.72 \pm \\
22.08\end{array}$ & 1.978 & 1.675 & 0.153 & 0.190 & 0.10 & 0.02 & 0.38 & 0.35 \\
\hline PSC Composites & & & & & & & & & & & & & & \\
\hline $\begin{array}{l}\text { 1.Teamwork } \\
\text { within units }\end{array}$ & $\begin{array}{l}76.97 \pm \\
32.04\end{array}$ & $\begin{array}{l}72.27 \pm \\
34.99\end{array}$ & $\begin{array}{l}82.89 \pm \\
26.70\end{array}$ & $73.85 \pm 35.44$ & $\begin{array}{l}89.47 \pm \\
21.46\end{array}$ & $\begin{array}{l}75.72 \pm \\
33.83\end{array}$ & 3.320 & 1.318 & $\begin{array}{l}0.047 \\
(a<c)\end{array}$ & 0.270 & 0.16 & 0.02 & 0.59 & 0.28 \\
\hline $\begin{array}{l}\text { 2. Management } \\
\text { expectations }\end{array}$ & $\begin{array}{l}80.26 \pm \\
19.42\end{array}$ & $\begin{array}{l}47.41 \pm \\
37.25\end{array}$ & $\begin{array}{l}67.76 \pm \\
30.71\end{array}$ & $48.42 \pm 35.17$ & $\begin{array}{l}76.97 \pm \\
26.88\end{array}$ & $\begin{array}{l}45.98 \pm \\
35.94\end{array}$ & 2.488 & 0.771 & 0.097 & 0.464 & 0.12 & 0.01 & 0.47 & 0.18 \\
\hline $\begin{array}{l}\text { 3. Teamwork } \\
\text { across units and } \\
\text { management } \\
\text { support }\end{array}$ & $\begin{array}{l}83.77 \pm \\
20.32\end{array}$ & $\begin{array}{l}49.81 \pm \\
33.33\end{array}$ & $\begin{array}{l}75.88 \pm \\
25.61\end{array}$ & $52.59 \pm 32.52$ & $\begin{array}{l}77.63 \pm \\
24.59\end{array}$ & $\begin{array}{l}50.10 \pm \\
34.26\end{array}$ & 2.172 & 1.850 & 0.129 & 0.160 & 0.11 & 0.02 & 0.42 & 0.38 \\
\hline $\begin{array}{l}\text { 4. Organizational } \\
\text { learning }\end{array}$ & $\begin{array}{l}60.53 \pm \\
24.33\end{array}$ & $\begin{array}{l}45.98 \pm \\
28.10\end{array}$ & $\begin{array}{l}56.14 \pm \\
23.39\end{array}$ & $47.32 \pm 26.62$ & $\begin{array}{l}63.16 \pm \\
16.96\end{array}$ & $\begin{array}{l}46.74 \pm \\
26.32\end{array}$ & 1.910 & 0.377 & 0.163 & 0.687 & 0.10 & 0.00 & 0.37 & 0.11 \\
\hline $\begin{array}{l}\text { 5. Overall } \\
\text { perceptions of } \\
\text { safety }\end{array}$ & $\begin{array}{l}75.66 \pm \\
26.94\end{array}$ & $\begin{array}{l}63.65 \pm \\
33.42\end{array}$ & $\begin{array}{l}73.03 \pm \\
28.70\end{array}$ & $64.37 \pm 31.38$ & $\begin{array}{l}75.66 \pm \\
26.94\end{array}$ & $\begin{array}{l}63.94 \pm \\
31.63\end{array}$ & 0.274 & 0.103 & 0.762 & 0.902 & 0.02 & 0.00 & 0.09 & 0.07 \\
\hline $\begin{array}{l}\text { 6. Openness with } \\
\text { feedback and } \\
\text { communication } \\
\text { regarding errors }\end{array}$ & $\begin{array}{l}85.96 \pm \\
16.22\end{array}$ & $\begin{array}{l}57.85 \pm \\
34.69\end{array}$ & $\begin{array}{l}77.63 \pm \\
29.83\end{array}$ & $60.06 \pm 32.25$ & $\begin{array}{l}84.21 \pm \\
20.85\end{array}$ & $\begin{array}{l}55.84 \pm \\
32.89\end{array}$ & 1.413 & 2.745 & 0.257 & 0.067 & 0.07 & 0.03 & 0.28 & 0.54 \\
\hline $\begin{array}{l}\text { 7. Frequency of } \\
\text { events reported }\end{array}$ & $\begin{array}{l}58.77 \pm \\
44.81\end{array}$ & $\begin{array}{l}40.42 \pm \\
45.13\end{array}$ & $\begin{array}{l}43.86 \pm \\
46.57\end{array}$ & $43.49 \pm 46.10$ & $\begin{array}{l}56.14 \pm \\
47.84\end{array}$ & $\begin{array}{l}41.19 \pm \\
45.57\end{array}$ & 2.096 & 0.932 & 0.138 & 0.396 & 0.10 & 0.01 & 0.40 & 0.21 \\
\hline 8. Staffing & $\begin{array}{l}33.33 \pm \\
23.25\end{array}$ & $\begin{array}{l}32.95 \pm \\
24.57\end{array}$ & $\begin{array}{l}36.84 \pm \\
24.25\end{array}$ & $31.03 \pm 22.83$ & $\begin{array}{l}40.35 \pm \\
25.89\end{array}$ & $\begin{array}{l}34.67 \pm \\
23.05\end{array}$ & 1.193 & 2.578 & 0.315 & 0.079 & 0.06 & 0.03 & 0.24 & 0.51 \\
\hline $\begin{array}{l}\text { 9. Handoffs and } \\
\text { transitions }\end{array}$ & $\begin{array}{l}75.26 \pm \\
26.07\end{array}$ & $\begin{array}{l}64.94 \pm \\
30.35\end{array}$ & $\begin{array}{l}66.84 \pm \\
29.87\end{array}$ & $66.32 \pm 30.01$ & $\begin{array}{l}74.74 \pm \\
30.38\end{array}$ & $\begin{array}{l}64.25 \pm \\
32.15\end{array}$ & 2.066 & 0.785 & 0.141 & 0.458 & 0.10 & 0.01 & 0.40 & 0.18 \\
\hline $\begin{array}{l}\text { 10. Nonpunitive } \\
\text { responses to error }\end{array}$ & $\begin{array}{l}32.89 \pm \\
29.70\end{array}$ & $\begin{array}{l}33.76 \pm \\
30.98\end{array}$ & $\begin{array}{l}42.11 \pm \\
32.93\end{array}$ & $34.20 \pm 29.60$ & $\begin{array}{l}40.13 \pm \\
26.98\end{array}$ & $\begin{array}{l}36.78 \pm \\
31.54\end{array}$ & 2.076 & 1.174 & 0.140 & 0.312 & 0.10 & 0.01 & 0.40 & 0.26 \\
\hline
\end{tabular}

Note. F: Repeated measures analysis of variance; SD: 2 (advanced analysis Bonferroni test), standard deviation; PSC: patient safety culture; UCN: unit charge nurse;SN:staff nurse

agree/always). In this study, the survey was completed by both UCNs and staff nurses who work with the UCNs. The survey was assessed based on the mean scores of positive answers (scores of either 4 or 5) (23). In Bodur and Filiz's study, the Cronbach's alpha coefficient was 0.86 (24). In this study, Cronbach's alpha coefficients were 0.90 .

\section{Data Analysis}

The IBM SPSS Statistics 22 (Chicago, IL) was used for the statistical analysis. During the comparison of the mean scores of the scales from the three measurements, the repeated measures of the analyses of the variance (the posthoc analysis and the Bonferroni test) were used for the normally distributed data, and the Friedman analysis (advanced analysis, Bonferroni-corrected, and Wilcoxon signed-rank test) was used for the abnormally distributed data. The Cochran's $Q$ test was used to analyze the difference between the three assessments of the HSOPSC regarding the number of events reported. The significance level was $p<0.05$. Büyüköztürk (25) reported $\eta 2$ ranges between 0.00 and 1.00 , and the values of $0.01,0.06$, and 0.14 were interpreted as "low," "moderate," and "high" effect sizes, respectively.

\section{Ethical considerations}

The Non-invasive Ethics Committee gave ethical approval to conduct this study (Date: 04.07.2017, 
Table 3. UCNs' (n: 38) and Staff Nurses' (n: 174) Reported Events in the Hospital Survey on PSC

\begin{tabular}{|c|c|c|c|c|c|c|c|c|c|c|c|c|}
\hline \multirow{3}{*}{$\begin{array}{l}\text { Reported Event } \\
\text { Numbers }\end{array}$} & \multicolumn{4}{|c|}{$\begin{array}{l}\text { First } \\
\text { Assessment (a) }\end{array}$} & \multicolumn{4}{|c|}{$\begin{array}{l}\text { Second } \\
\text { Assessment (b) }\end{array}$} & \multicolumn{4}{|c|}{$\begin{array}{l}\text { Third } \\
\text { Assessment (c) }\end{array}$} \\
\hline & \multicolumn{2}{|c|}{ UCN } & \multicolumn{2}{|l|}{ SN } & \multicolumn{2}{|c|}{ UCN } & \multicolumn{2}{|l|}{ SN } & \multicolumn{2}{|c|}{ UCN } & \multicolumn{2}{|l|}{ SN } \\
\hline & $\mathbf{n}$ & $\%$ & $\mathbf{n}$ & $\%$ & $\mathbf{n}$ & $\%$ & $\mathbf{n}$ & $\%$ & $\mathbf{n}$ & $\%$ & $\mathbf{n}$ & $\%$ \\
\hline None & 18 & 47.4 & 138 & 79.3 & 14 & 36.8 & 138 & 79.3 & 4 & 10.5 & 123 & 70.7 \\
\hline 1 or 2 events & 13 & 34.2 & 29 & 16.7 & 10 & 26.3 & 29 & 16.7 & 17 & 44.7 & 38 & 21.8 \\
\hline 3 to 5 events & 4 & 10.5 & 5 & 2.9 & 11 & 28.9 & 5 & 2.9 & 10 & 26.3 & 11 & 6.3 \\
\hline$\geq 6$ events & 3 & 7.9 & 2 & 1.1 & 3 & 7.9 & 2 & 1.1 & 7 & 18.4 & 2 & 1.1 \\
\hline No & 18 & 47.4 & 138 & 79.3 & 14 & 36.8 & 138 & 79.3 & 4 & 10.5 & 123 & 70.7 \\
\hline Yes & 20 & 52.6 & 36 & 20.7 & 24 & 63.2 & 36 & 20.7 & 34 & 89.5 & 51 & 29.3 \\
\hline Cochran's Q (SD: 2) & \multicolumn{12}{|c|}{ UCNs: $17.333 ;$ SNs: 10.714} \\
\hline$p$ & \multicolumn{12}{|c|}{ UCNs: $.000(a, b<c)+$; SNs: $.005(a, b<c) \dagger$} \\
\hline
\end{tabular}

Note. + Assessed based on positive responses; SD: standard deviation; UCN: unit charge nurse; SN: staff nurse.

Decision No: GO 17/573). The researcher also obtained written consent from the UCNs and staff nurses who participated in the study. The necessary permission was obtained from the authors who developed the data collection tools and conducted the validity and reliability study. Research and publication ethics were followed in the article.

\section{RESULTS}

The average age of the UCNs was 40.34 years (SD $=6.05$ ); their average number of working years was $19.18(S D=7.44)$, and their average working experience as $U C N$ s was 3.91 years $(S D=4.75)$. The percentage of the UCNs who worked more than 40 hours in a week was $55.3 \%$. Half of them had previously received training on patient safety. The average age of the staff nurses was 35.18 years ( $S D$ $=6.77$ ); their average working period was 13.67 years $(S D=7.74)$, and the average amount of time they had been working with UCNs was 1.31 years $(S D=1.51)$. The percentage of staff nurses who worked more than 40 hours per week was $60.5 \%$, and $76.4 \%$ had previously received training on patient safety.

The UCNs' mean scores on the psychological empowerment meaning and competence subscales were significantly higher in the third assessment respectively, $(20.24 \pm 1.26$ and $20.32 \pm 0.96$, $)$ than in the first $(19.61 \pm 1.39$ and $19.71 \pm 1.75,[p<0.05])$.
No statistically significant differences were observed in either the mean scores of the other two subscales or in total psychological empowerment $(p>0.05$ [Table 1]). The UCNs' mean positive response for teamwork within the units was significantly higher in the third assessment $(89.47 \pm 21.46)$ than in the first $(76.97 \pm 32.04 ; p<0.05)$. No significant difference was found between the mean positive response percentages for the total PSC and the nine composites $(p>0.05)$. No significant difference was found between the staff nurses' PSC total mean positive response percentages and the mean positive response percentages for the ten composites obtained from the three assessments $(p>0.05$; Table 2). The numbers of UCNs and staff nurses' reported events increased significantly in the second and third assessments $(p<0.001$; Table 3$)$.

\section{DISCUSSION}

There is a positive relationship between educational interventions and psychological empowerment (6), and educational interventions also contribute to developing PSC perceptions and decreasing sentinel events (14-18). In this study, we developed a trainingbased empowerment program to empower the UCNs psychologically and improve PSC perceptions of the UCNs and staff nurses. 
There were improvements in meaning and competence, and teamwork within the units (composite), and the number of reported events after the implementation of empowerment program. However, these findings should be considered because this was a study with a single group, prepost design, and other factors that may have affected the development. Although no studies have been conducted to analyze the effect of an empowerment program on UCNs' psychological empowerment perceptions, psychodrama (26) and training-based psychological empowerment programs do increase nurses' psychological empowerment (competence and impact) (12). In this study, the empowerment program developed the UCNs' perception of meaning. It increased the fit between the nurses' work role requirements and their beliefs, values, and behaviors. The program increased their awareness of their abilities and capabilities to do more. Employees have more willingness and fortitude to work in a job in which they can use their abilities when they are sure of their competence (27). Therefore, the UCNs who feel competent in the hospital and perceive their job as meaningful may provide an advantage in creating a PSC. The program did not provide an improvement in autonomy and impact subdimensions of psychological empowerment. These dimensions are related to the structural characteristics of institutions that should be provided by the administration. Since these are issues related to management, it is a natural consequence that the empowerment program did not affect them. (28).

The empowerment program improved the teamwork within units. The authors of previous studies have reported similar results $(15,17)$. To ensure a positive PSC with sufficient group work, the team should share patient safety problems and then produce solutions. In addition, teamwork is very important in reducing health-related infections and creating a safety culture (29). Therefore, group work and staff nurses' inclusion in some individual activities by the UCNs contributed to this composite's development. On the other hand, the program did not improve the nurses' perceptions of the total PSC or other nine composites; this is in keeping with previous studies' findings $(15,17)$. Structures and processes should be included, and attitudes, beliefs, and behaviors should be addressed to create a PSC in the institution. Therefore, creating and maintaining a desirable PSC in health institutions is a complicated and lengthy process (2).
Similarly, Michel et al. (30) stated that it could take five years to develop a safety culture that permeates an entire organization. Since PSC is a phenomenon that changes over a long period, it is recommended that it be evaluated every 18 to 24 months (23). The authors of a similar study reported positive results in PSC at the end of a three-year intervention involving staff nurses (31). However, no positive change was observed in the staff nurses' perceptions in this study. This may be due to the empowerment program's indirect provision to the staff nurses and the study's duration. The other improvement was observed in the number of events reported by UCNs and staff nurses after implementing the program which raises the following questions: Did the number of medical errors increase? Or did a positive PSC develop because of the program? The discussions, interviews, and workgroups regarding personnel training and errors led to an increase in reporting rate $(31,32)$. Therefore, it can be concluded that the elements of this study were effective in influencing event reporting. This study is the first to develop UCNs, and staff nurses' perceptions of PSC that were examined together with implementing an empowerment program. The implementation of group work focused on the solutions to related real patient safety problems experienced by UCNs constitutes another original aspect of this study.

\section{Limitation}

Despite the critical results, the absence of a control group is the main limitation that may affect the study results' validity. It has been stated in the literature that a single-group, and the pretest-posttest design provides limited evidence to support claims regarding the effectiveness of an intervention (33).

\section{CONCLUSIONS}

The intervention improved UCNs competence and attaching meaning to their job. Therefore, running similar programs with nurse managers and monitoring the results is recommended. Ensuring that the UCNs can positively affect the work environment, organize and assess nursing practices freely, make decisions on patient care independently, and account for these decisions' outcomes where a PSC is desired.

The program improved the Teamwork within the units composite of PSC. Furthermore, the empowerment program's positive effect on the number of reported events indicates that a significant awareness was 
raised in the staff nurses and the UCNs about PSC. Therefore, such programs can also be recommended to develop teamwork in hospitals and error reporting. This study also shows that creating a positive PSC requires a review of the structures and processes of an organization. This is why creating and maintaining a desirable PSC in health institutions is a long process. The duration of future empowerment programs may be determined to allow for the longterm monitoring of their effects.

Additionally, all employees may contribute to the creation of a safety culture. Hence, this program may be multidisciplinary and include patients/patients' relatives' participation, and its effects may be assessed through prospective studies in terms of patients, employees, and organizational outcomes. Further randomized controlled studies are needed to determine the effect of the program. We recommend that future PSC studies be planned for longer periods and applied to all healthcare professionals.

Acknowledgements: This article is extracted from the first author's doctorate dissertation entitled "The Effects of Unit Charge Nurse's Empowerment Program on Nurses' Perceptions of Empowerment, Control of Nursing Practices and Patient Safety Culture." (PhD Dissertation, Hacettepe University, Ankara, Turkey, 2019).

This article was presented as an oral presentation at the $1^{\text {st }}$ International Congress of Multidisciplinary Studies in Health Sciences Ankara/Turkey.Date : 3-5 June 2020

Conflict of Interest: The authors declare no competing financial interests and no sources of funding and support, including any for equipment and medications.

Peer-review: Externally peer-reviewed.

\section{REFERENCES}

1. World Health Organization. (2020). Patient safety. Retrieved from: https://www.who.int/health-topics/patientsafety\#tab=tab_2. Date of access:12.03.2020.

2. Campione J, Famolaro T. Promising Practices for Improving Hospital Patient Safety Culture. The Joint Commission Journal on Quality and Patient Safety 2018;44:23-32.

3. Singer S, Lin S, Falwell A, Gaba D, Baker L. Relationship of safety climate and safety performance in hospitals. Health Services Research 2009;44:399-421.

4. Kim KJ, Yoo MS, Seo EJ. Exploring the Influence of Nursing Work Environment and Patient Safety Culture on Missed Nursing Care in Korea. Asian Nursing Research 2018; 12:121-126.
5. Trus M, Doran D, Martinkenas A, Asikainen $\mathrm{P}$, Suominen T. Perception of work-related empowerment of nurse managers. Journal of Research in Nursing 2018;23:317-330.

6. Voegtlin C, A Boehm, S, Bruch H. How to empower employees: using training to enhance work units' collective empowerment. International Journal of Manpower 2015; 36:354373.

7. Oducado RMF. Leader Empowering Behaviors and Psychological Empowerment as Perceived by Young Hospital Staff Nurses: A Pilot Study. Jurnal Ners 2019;14:47-54.

8. Laschinger HKS, Fida R. Linking nurses' perceptions of patient care quality to job satisfaction: The role of authentic leadership and empowering professional practice environments. Journal of Nursing Administration 2015;45:276283.

9. Conger JA, Kanung RN. The empowerment process: Integrating theory and practice. Academy of Management Review 1998:13;471428.

10. Thomas KW, Velthouse BA. Cognitive elements of empowerment: An interpretive model of intrinsic task motivation. Management Review 1990;15:666-681.

11. Spreitzer GM. Psychological empowerment in the workplace: Dimensions, measurement, and validation. Academy of Management Journal 1995;38:1442-1465.

12. Chang LC, Liu CH, Yen EH. Effects of an empowerment-based education program for public health nurses in Taiwan. Journal of Clinical Nursing 2008;17:2782-90.

13. Han Y, Kim JS, Seo Y. Cross-Sectional Study on Patient Safety Culture, Patient Safety Competency, and Adverse Events. West J Nurs Res 2020;42:32-40.

14. Ginsburg L, Norton PG, Casebeer A, Lewis S. An Educational Intervention to Enhance Nurse Leaders' Perceptions of Patient Safety Culture. HSR: Health Services Research 2005;40:9971020.

15. AbuAIRub RF, Abualhaja AA. The Impact of Educational Interventions on Enhancing Perceptions of Patient Safety Culture Among Jordanian Senior Nurses. Nursing Forum 2014;49:139-50.

16. Xie J, Ding S, Zhong Z, et al. A safety culture training program enhanced the perceptions of 
the patient safety culture of nurse managers. Nurse Education in Practice 2017;27:128-133.

17. Amiri M, Khademian Z, Nikandish R. The effect of nurse empowerment educational program on patient safety culture: a randomized controlled trial. MC Medical Education 2018;18:158.

18. Habahbeh AA, Alkhalaileh MA. Effect of an educational program on the attitudes towards patient safety of operation room nurses. British Journal of Nursing 2020;29: 222-228.

19. Cranmer CA. One-Group Pretest-Posttest Design (In The SAGE Encyclopedia of Communication Research Methods, Editors: Allen M.). Thousand Oaks; SAGE Publications 2017;1125-1126. Available from: https://methods.sagepub.com/base/download/R eferenceEntry/the-sage-encyclopedia-ofcommunication-research-methods/i9778.xml.

20. Leadership Practice Inventory. (LPI) (2021). Online-how many observers? Retrieved from https://support.leadershipchallenge.com/s/articl e/lpi9 online-selecting-observers.

21. Huber DL. Management Principles. Huber, D.L. (Ed.). Leadership and Nursing Care Management. 4. Edition Saunders Elsevier, Missouri. 2010

22. Uner S, Turan S. The construct validity and reliability of the Turkish version of Spreitzer's psychological empowerment scale. BMC Public Health 2010;10:117.

23. Sorra J, Yount N, Famolaro T, et al. AHRQ Hospital Survey on Patient Safety Culture Version 2.0: User's Guide. (Prepared by Westat, under Contract No. HHSP233201500026I/ HHSP23337004T). Rockville, MD: Agency for Healthcare Research and Quality; September 2019. AHRQ Publication No. 19-0076. https://www.ahrq.gov/sops/surveys/hospital/ index.html.

24. Bodur S, Filiz E. Validity and reliability of Turkish version of hospital survey on patient safety culture and perception of patient safety in public hospitals in Turkey. BMC Health Services Research 2010;10:28-36.

25. Büyüköztürk Ş. Büyüköztürk Ş. Data analysis handbook for social sciences: Statistics, research design, SPSS applications and interpretation (Extended 5th edition). 2005. Ankara: Pegem publications.

26. Atlı Özbaş A, Tel H. The effect of a psychological empowerment program based on psychodrama on empowerment perception and burnout levels in oncology nurses: Psychological empowerment in oncology nurses. Palliat Support Care 2016;14:393-401.

27. Spreitzer GM. Taking stock: A review of more than twenty years of research on empowerment at work. In C. Cooper, \& J. Barling (Eds.), The Handbook of Organizational Behavior. Thousand Oaks, CA: Sage Publications. 2007;54-72.

28. Yıldız A, Kaya S, Teleş M, Korku C. The effect of nurses' empowerment perceptions on job safety behaviours: a research study in Turkey. International Journal of Occupational Safety and Ergonomics 2018;26:489-496

29. Profit J, Sharek PJ, Cui X, et al. The Correlation Between Neonatal Intensive Care Unit Safety Culture and Quality of Care. Journal of Patient Safety 2020;16:310-316.

30. Mitchell I, Schuster A, Smith K, Pronovost $P, W u$ A. Patient safety incident reporting: a qualitative study of thoughts and perceptions of experts 15 years after 'To Err is Human.' BMJ Quality and Safety 2016;25:92-99.

31. Kuosmanen A, Tiihonen J, Repo-Tiihonen E, Eronen $\mathrm{M}$, Turunen $\mathrm{H}$. Changes in Patient Safety Culture: A Patient Safety Intervention for Finnish Forensic Psychiatric Hospital Staff. Journal of Nursing Management 2019;27:848857.

32. Verbakel N, Langelaan M, Verheij T, Wagner C, Zwart D. Effects of patient safety culture interventions on incident reporting in general practice: a cluster-randomized trial. British Journal of General Practice 2015;65:319-329.

33. Spurlock DR. The single-group, pre-and posttest design in nursing education research: it is time to move on. J Nurs Educ 2015;57:69-71. 